\begin{tabular}{l} 
JOURNAL OF APPLIED SMART ELECTRICAL \\
NETWORK AND SYSTEMS (JASENS) \\
\hline ISAS
\end{tabular}

\title{
Desain Fuzzy Logic Controller Untuk Pengendali Pergerakan Mobile Manipulator
}

\author{
Putri Repina Kesuma ${ }^{1}$, Tresna Dewi ${ }^{2}$, RD Kusumanto ${ }^{3}$, Pola Risma ${ }^{4}$, Yurni Oktarina ${ }^{5}$ \\ ${ }^{1}$ Jurusan Teknik Elektro, Politeknik Negeri Sriwijaya \\ 2tresna_dewi@polsri.co.id*
}

\begin{abstract}
Technology is developing more and more to facilitate human life. Technology enables automation in all areas of life, and robots are among the most frequently used machines in automation. Robots can help with human work in all fields, including agriculture. A mobile robot manipulator is a combination of a robot arm and a mobile robot so that this type of robot can combine the capabilities of the two robots. This paper discusses the design of a robot manipulator to be used in agriculture to replace farmers in the harvesting of agricultural products, such as tomatoes. This paper presents a mechanical, electrical design and uses the Fuzzy Logic Controller as artificial intelligence. The feasibility of the proposed method is demonstrated by simulation in Mobotsim.
\end{abstract}

Keywords: Mobile Manipulator, Mobile Robot, Fuzzy Logic.

\begin{abstract}
Abstrak
Teknologi semakin berkembang untuk memudahkan kehidupan manusia. Teknologi memungkinkan otomatisasi diseluruh bidang kehidupan, dan salah satu mesin yang paling sering digunakan dalam otomasi adalah robot. Robot dapat membantu pekerjaan manusia di semua bidang, termasuk bidang pertanian. Mobile robot manipulator adalah gabungan antara arm robot dan mobile robot, sehingga robot jenis ini mampu menggabungkan kemampuan dua robot tersebut. Paper ini membahas desain robot manipulator yang akan diaplikasikan pada bidang pertanian untuk menggantikan petani dalam memanen produk pertanian, contohnya buat tomat. Paper ini menyajikan desain mekanis, elektris, dan mengaplikasikan Fuzzy Logic Controller sebagai kecerdasan buatan. Untuk membuktikan efektivitas metode yang disajikan pada paper ini, maka dilakukan simulasi dengan program Mobotsim.
\end{abstract}

Kata kunci: Mobile Manipulator, Mobile Robot, Fuzzy Logic

Diterima Redaksi : 01-06-2020 | Selesai Revisi : 09-06-2020 | Diterbitkan Online : 30-06-2020

\section{Pendahuluan}

Perkembangan ilmu pengetahuan dan teknologi semakin berkembang, salah satunya ditandai dengan banyaknya alat-alat yang diciptakan dan dikendalikan secara otomatis. Peralatan otomatis ini banyak digunakan manusia untuk membantu dalam meringankan pekerjaan mereka. Salah satu contoh alat yang dapat meringankan pekerjaan manusia adalah robot. Robot merupakan alat yang dapat membantu manusia dalam mengerjakan pekerjaan yang sulit dijangkau manusia dan dapat mempercepat waktu proses pengerjaannya. Salah satu jenis robot yang dapat digunakan adalah robot mobile manipulator. Robot mobile manipulator merupakan gabungan antara mobile robot dan robot manipulator atau arm robot. Mobile robot merupakan jenis robot yang dapat bergerak dari satu tempat ke tempat lain, sedangkan robot manipulator atau arm robot merupakan jenis robot yang dapat mengambil dan memindahkan benda atau barang tetapi tidak dapat berpindah tempat [1-7]. Sehingga, robot mobile manipulator berfungsi sebagai robot yang mengambil benda dan dapat memindahkan benda tersebut dari satu tempat ke tempat lain. Robot ini juga banyak digunakan pada bidang industri salah satunya adalah industri pertanian. Sebagai contohnya, yaitu untuk memetik buah dan mengambil serta membawa buah tersebut ke tempat yang telah disediakan [8-10]. 
Dalam perancangan sebuah robot, salah satu komponen yang banyak digunakan adalah sensor. Sensor ini digunakan sebagai input pada sebuah robot. Pada jurnal kali ini menggunakan sensor jarak dan camera. Sensor jarak digunakan pada mobile robot dan end effector agar dapat mendeteksi jarak antara robot dan benda. Sedangkan, camera digunakan sebagai pendeteksi warna pada benda.

Selain sensor yang digunakan sebagai input, robot juga membutuhkan metode yang dapat membantu robot dalam melakukan pergerakan. Metode untuk kendali gerak robot yang banyak digunakan yaitu, fuzzy logic [11-17], Neural network [18-24] dan Genetic Algorithm [25]. Output dari sensor ini yang digunakan sebagai input pada fuzzy logic. Tujuan digunakannya fuzzy logic pada robot adalah agar robot dapat mengambil keputusan yang cerdas dan bergerak sesuai dengan yang diinginkan [11-17].

Paper ini membahas desain robot manipulator yang akan diaplikasikan pada bidang pertanian untuk menggantikan petani dalam memanen produk pertanian, contohnya buat tomat. Paper ini menyajikan desain mekanis, elektris, dan mengaplikasikan Fuzzy Logic Controller sebagai kecerdasan buatan. Untuk membuktikan efektivitas metode yang disajikan pada paper ini, maka dilakukan simulasi dengan program Mobotsim.

\section{Metode Penelitian} Untuk mendapatkan hasil yang baik dan sesuai dengan robot lebih leluasa untuk bergerak di tanah/kebun, yang direncanakan, ada beberapa tahapan yang sehingga robot dapat membawa buah/sayur yang telah dilakukan dari metode fuzzy logic dalam mengontrol dipetik dan meletakkannya di keranjang yang terdapat gerak robot. Mulai dari penentuan input dan output pada bagian belakang robot (Gambar 3), serta yang digunakan, yaitu sensor jarak kemudian membawanya ke tempat yang telah ditentukan. penentuan nilai range pada tabel rules dan pergerakan robot dari hasil deteksi input yang digunakan.

\subsection{Design Mekanik}

Design mekanik robot mobile manipulator terdapat pada gambar berikut;;

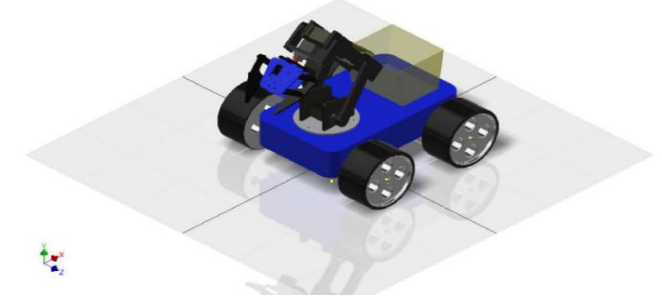

Gambar 1. Tampak Keseluruhan Robot Mobile Manipulator

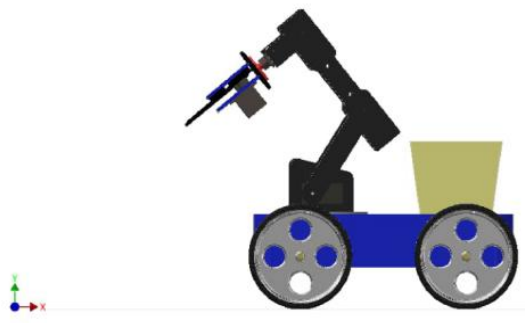

Gambar 2. Tampak Samping Robot Mobile Manipulator

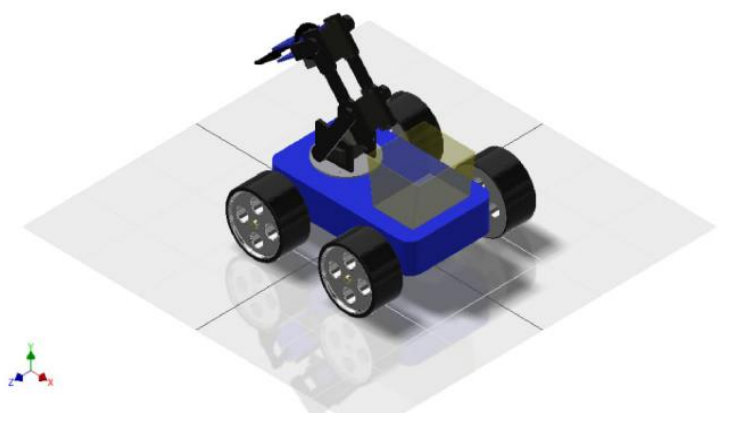

Gambar 3. Tampak Belakang Robot Mobile Manipulator

Dari gambar design mekanik tersebut dapat dilihat bahwa roda yang digunakan pada robot termasuk roda yang berdiameter cukup besar, hal ini dikarenakan agar

\subsection{Design Elektrik}

Gambar 5 menunjukkan design elektrik atau skematik rangkaian dari robot mobile manipulator. Pada design

elektrik tersebut komponen yang digunakan yaitu; sensor jarak, camera Pi, Raspberry Pi, Baterai Lippo, Arduino Mega, Motor Servo, Driver Motor (Modul 1293d) dan Motor DC. Baterai lippo pada rangkaian

digunakan sebagai sumber atau power supply. Pada saat camera mendeteksi buah dan akan diproses di Raspberry $P i$ serta sensor jarak yang terdapat pada end effector terdeteksi dekat, maka motor DC akan berhenti dan yang bergerak adalah motor servo nya yaitu untuk mengambil buah dan meletakkannya pada keranjang yang ada pada robot. Kemudian, apabila sensor jarak mendeteksi sedang atau jauh dan camera tidak mendeteksi warna maka motor servo akan diam dan motor DC akan terus bergerak hingga mendekati objek atau camera mendeteksi warna buah yang ditentukan. 


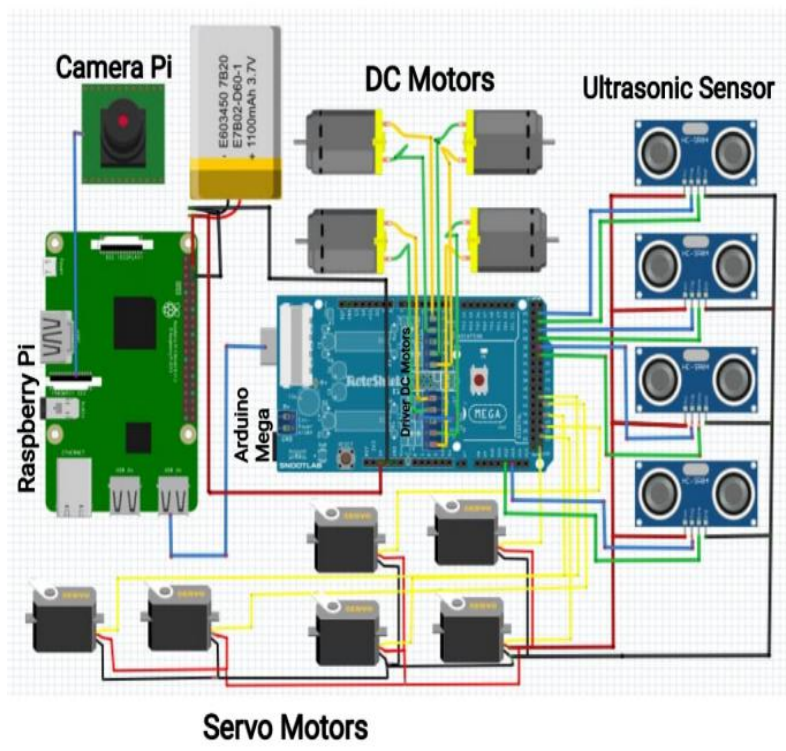

Gambar 4. Skematik Rangkaian Mobile Manipulator

\section{Hasil dan Pembahasan}

\subsection{Design Fuzzy Logic}

Fuzzy logic digunakan untuk menerjemahkan suatu besaran yang dinyatakan dengan menggunakan linguistic (ilmu bahasa). Contohnya yaitu dengan besaran kecepatan suatu kendaraan yang dinyatakan dengan stop, lambat, sedang dan cepat. Dalam hal ini fuzzy logic menunjukkan sejauh mana suatu nilai dapat dikatakan benar atau salah. Tidak seperti logika klasik atau tegas yang hanya mempunyai dua kemungkinan cepat atau lambat, fuzzy logic mempunyai kemungkinan yang lebih banyak. Oleh sebab itu fuzzy logic dapat dikatakan sebagian benar dan sebagian salah dalam waktu yang bersamaan [4].

Simulasi yang digunakan untuk perancangan fuzzy logic pada paper ini adalah aplikasi Scilab [7]. Ada

beberapa metode dalam mempresentasikan hasil dari fuzzy logic yaitu Sugeno, Tsukamoto dan Mamdani. Pada paper ini metode yang digunakan adalah metode Mamdani dengan bentuk kurva tringular. Jumlah

membership input nya adalah 4 sensor dan 1 kamera, sedangkan jumlah membership output nya adalah 8 output yang berupa 2 motor pada mobile robot dan 6

motor servo pada arm robot. Gambar kurva membership function input dapat dilihat pada Gambar 5.

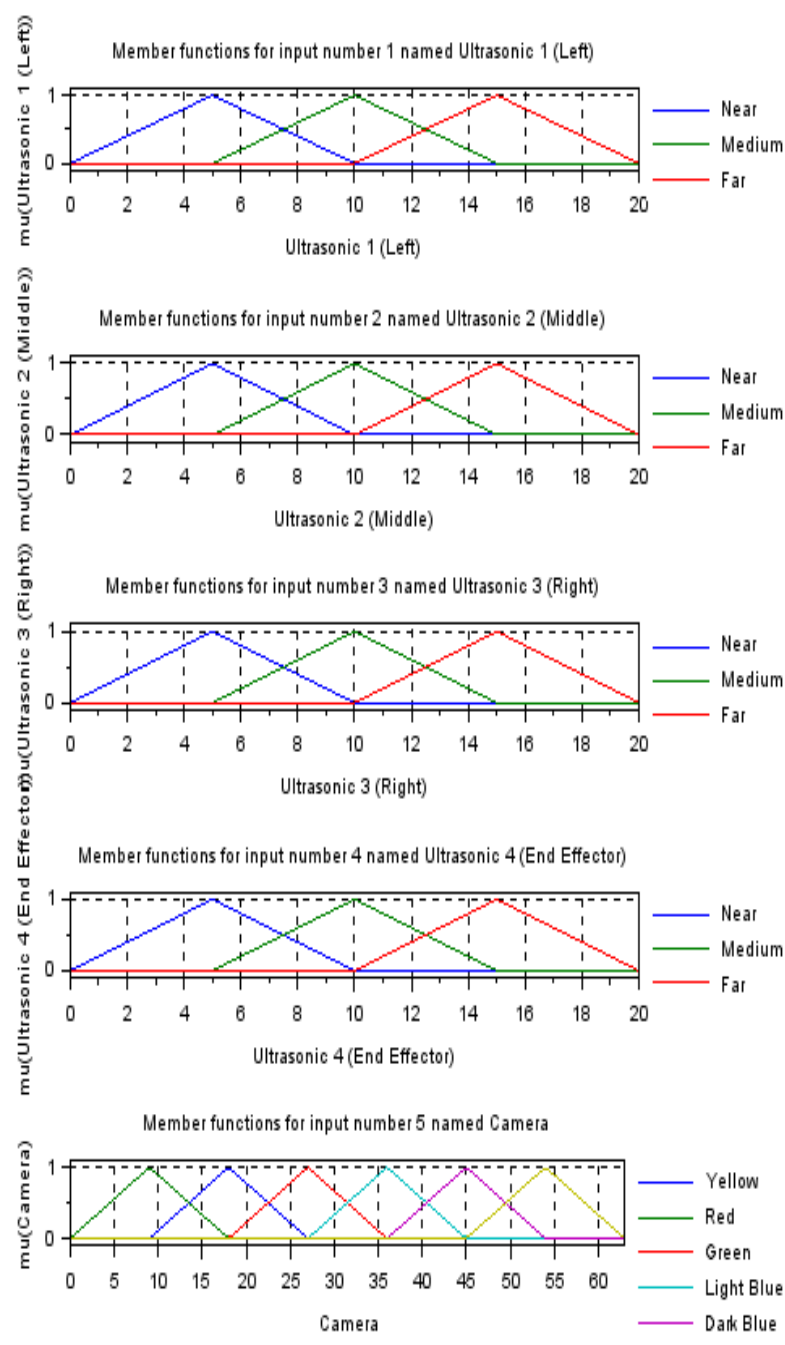

Gambar 5. Member Functions for Input

Pada Gambar 5 tersebut merupakan bentuk kurva dari input 4 sensor jarak dan 1 camera. Pada Gambar 5 ini juga terdapat variabel linguistik yang berupa kata/kalimat dan himpunan fuzzy yang berupa angka [16]-[19]. Sensor jarak atau ultrasonic mempunyai tiga variabel linguistik dengan himpunan fuzzy yaitu; Near (0-10), Medium (5-15) dan Far (10-20). Untuk camera mempunyai enam variabel linguistik dengan himpunan fuzzy yaitu; Yellow (9-27), Red (0-18), Green (18-36), Light Blue (27-45), Dark Blue (36-54) dan Pink (45-63).

Gambar kurva membership function output terdapat pada Gambar 6a dan Gambar 6b, gambar membership function output terbagi menjadi dua gambar dikarenakan jumlah output yang banyak dan agar grafik dapat terlihat dengan jelas. 

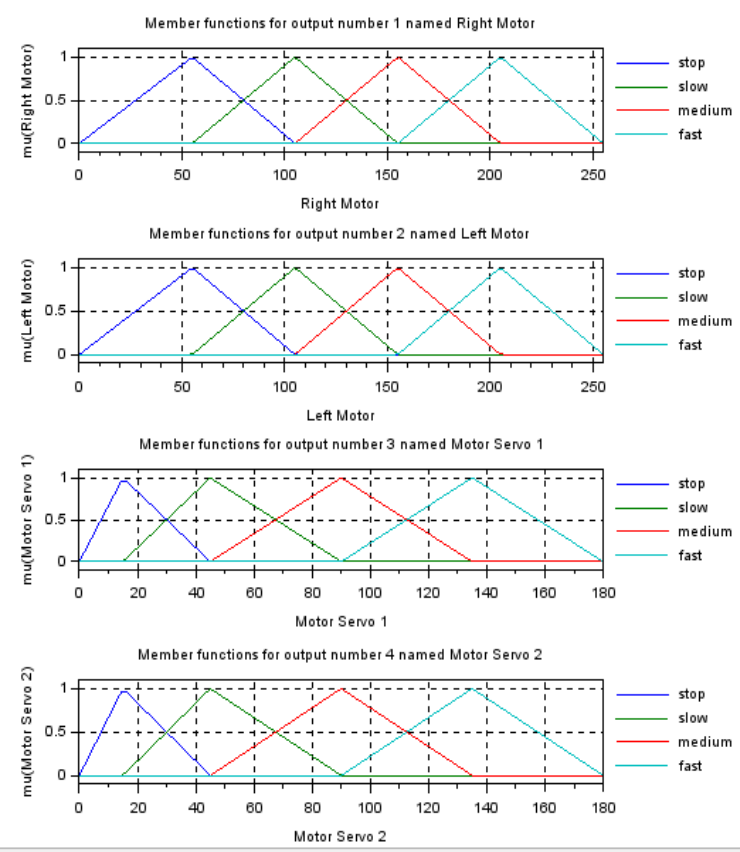

Gambar 6a. Member Functions for Output
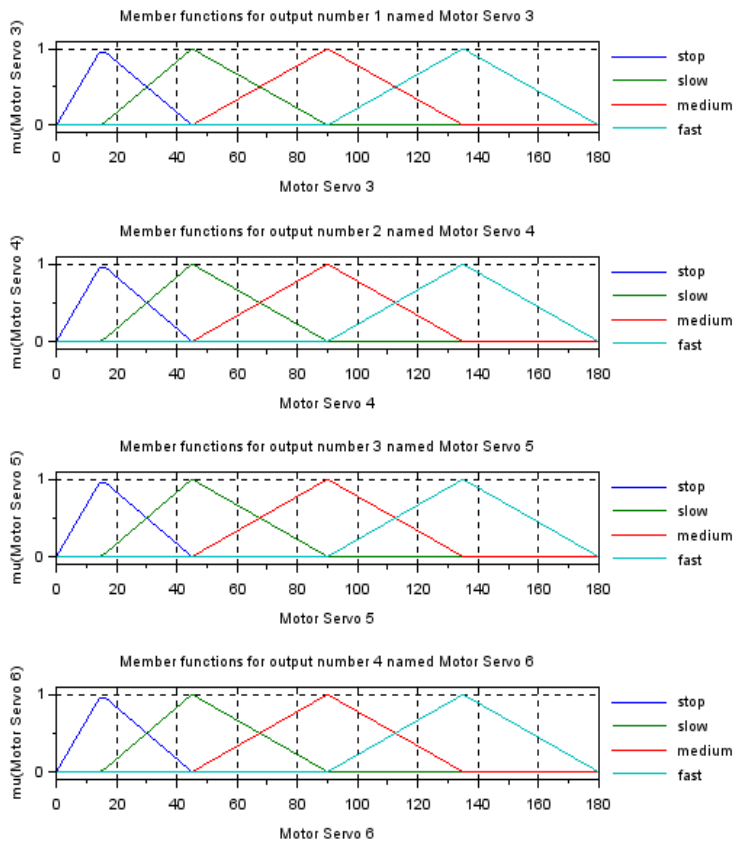

Gambar 6b. Member Functions for Output

Pada Gambar 7a dan Gambar 7b merupakan bentuk kurva dari membership function output yang terdiri dari 2 motor DC dan 6 motor servo. Motor DC mempunyai empat variabel linguistik dengan himpunan fuzzy yaitu; stop (0-105), slow (55-155), medium (105-205) dan fast (155-255). Untuk motor servo juga mempunyai empat variabel linguistik dengan himpunan fuzzy yaitu; stop (0-45), slow (15-90), medium (45-135) dan fast (90-180).
Setelah menentukan membership function input dan membership function output, selanjutnya adalah membuat rules seperti pada Tabel 1. Rules tersebut menjelaskan bahwa pada saat robot berjalan dan camera mendeteksi adanya buah, maka mobile robot akan berhenti dan arm robot akan bergerak mengambil buah serta memindahkan buah tersebut. Setelah arm robot kembali ke posisi semula, maka mobile robot akan bergerak lagi. Warna yang dideteksi oleh camera adalah warna Yellow. Apabila camera tidak mendeteksi warna Yelow maka arm robot akan diam dan mobile robot tetap bergerak.

Tabel 1. Rules pada Robot Mobile Manipulator

\begin{tabular}{|c|c|c|c|c|c|c|c|c|c|c|c|c|c|}
\hline & & Input & & & & & & & utput & & & & \\
\hline $\begin{array}{c}\text { Ultraso } \\
\text { nic 1 } \\
\text { (Left) }\end{array}$ & $\begin{array}{l}\text { Ultraso } \\
\text { nic 2 } \\
\text { (Middle }\end{array}$ & $\begin{array}{c}\text { Ultrason } \\
\text { ic } 3 \\
\text { (Right) }\end{array}$ & $\begin{array}{l}\text { Ultrasonic } 4 \\
\text { (End } \\
\text { Effector) }\end{array}$ & Camera & $\begin{array}{l}\text { Right } \\
\text { Motor }\end{array}$ & $\begin{array}{l}\text { Left } \\
\text { Motor }\end{array}$ & $\begin{array}{l}\text { Motor } \\
\text { Servo } \\
1\end{array}$ & $\begin{array}{l}\text { Motor } \\
\text { Servo } \\
2\end{array}$ & $\begin{array}{l}\text { Motor } \\
\text { Servo } \\
3\end{array}$ & $\begin{array}{l}\text { Motor } \\
\text { Servo } \\
4\end{array}$ & $\begin{array}{l}\text { Motor } \\
\text { Servo } \\
5\end{array}$ & $\begin{array}{c}\text { Motor } \\
\text { Servo } 6\end{array}$ & $\begin{array}{l}\text { nilan } \\
\text { ilie } \\
\text { ot }\end{array}$ \\
\hline Near & Near & Near & Near & Yellow & stop & stop & slow & slow & slow & slow & slow & slow & berhen \\
\hline Iedium & Near & Near & Medium & Yellow & stop & stop & $\underset{\mathrm{m}}{\stackrel{\text { mediu }}{\mathrm{m}}}$ & $\underset{\mathrm{m}}{\text { mediu }}$ & $\underset{\mathrm{m}}{\operatorname{mediu}}$ & $\underset{\mathrm{m}}{\text { mediu }}$ & $\underset{\mathrm{m}}{\stackrel{\text { mediu }}{\mathrm{m}}}$ & medium & berthenti \\
\hline Far & Near & Near & Far & Yellow & stop & stop & fast & fast & fast & fast & fast & fast & berhenti \\
\hline Near & Medium & Near & Near & Red & slow & slow & stop & stop & stop & stop & stop & stop & maju \\
\hline edium & Medium & Near & Medium & Red & slow & $\underset{\mathrm{m}}{\substack{\text { mediu } \\
\mathrm{m}}}$ & stop & stop & stop & stop & stop & stop & $\begin{array}{l}\text { serong } \\
\text { kanan }\end{array}$ \\
\hline Far & Medium & Near & Far & Red & slow & fast & stop & stop & stop & stop & stop & stop & belok ki \\
\hline Near & Far & Nea & Near & een & slow & slow & stop & stop & stop & op & op & stop & maju \\
\hline Medium & Far & Near & Medium & Green & slow & $\underset{\mathrm{m}}{\text { mediu }}$ & stop & stop & stop & stop & stop & stop & $\begin{array}{l}\text { serong } \\
\text { kanan }\end{array}$ \\
\hline Far & Far & Nea & Fa & Green & slow & fast & stop & stop & stop & stop & stop & stop & elok k \\
\hline Near & Near & Medium & Near & Blue & medium & slow & stop & stop & stop & op & op & stop & erong \\
\hline dium & Near & Medium & Medium & Blue & medium & $\underset{\mathrm{m}}{\mathrm{mediu}}$ & stop & stop & stop & stop & stop & stop & maju \\
\hline Far & Near & Medium & Far & & slow & fast & stop & stop & stop & stop & stop & stop & belok ka \\
\hline Near & Medium & Medium & $\mathrm{Ne}$ & Dark Blue & medium & slow & stop & stop & stop & stop & stop & stop & serong ! \\
\hline edium & Medium & Medium & Medium & Dark Blue & medium & $\begin{array}{c}\text { mediu } \\
\text { m }\end{array}$ & stop & stop & stop & stop & stop & stop & maju \\
\hline Far & Medium & Med & Far & Dark Blue & medium & fast & stop & stop & stop & stop & stop & pp & \\
\hline Near & $\mathrm{Fa}$ & Me & $\mathrm{N}$ & Pink & medium & slow & stop & stop & stop & p & p & op & erons. \\
\hline Iedium & Far & Medium & Medium & Pink & medium & $\begin{array}{c}\text { mediu } \\
\mathrm{m}\end{array}$ & stop & stop & , & stop & stop & stop & 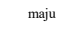 \\
\hline Far & Far & Medium & $\mathrm{Fa}$ & Pink & medium & fast & stop & stop & stop & stop & stop & stop & belok ka \\
\hline Near & Near & $\mathrm{Fa}$ & $\mathrm{Ne}^{\mathrm{C}}$ & Yellow & sto & stop & slow & slow & slow & slow & slow & slow & berhenti \\
\hline Medium & $\mathrm{Ne}$ & Far & Mediu & Yellow & stop & stop & $\underset{\mathrm{m}}{\stackrel{\text { mediu }}{\text { mats }}}$ & $\underset{\mathrm{m}}{\substack{\text { mediu } \\
\mathrm{m}}}$ & $\underset{\mathrm{m}}{\text { mediu }}$ & $\underset{\mathrm{m}}{\text { mediu }}$ & $\underset{\mathrm{m}}{\stackrel{\text { mediu }}{\mathrm{m}}}$ & medium & berhenti \\
\hline Far & $\mathrm{Ne}$ & Far & $\mathrm{Fa}$ & Yellow & stop & stop & fast & fast & fast & fast & fast & fast & berhenti \\
\hline Near & Medium & Far & $\mathrm{Ne}$ & Red & medium & slow & stop & stop & stop & stop & stop & stop & serong kiri \\
\hline Medium & Medium & Far & Medium & Red & medium & $\begin{array}{c}\text { mediu } \\
\mathrm{m}\end{array}$ & stop & stop & stop & stop & stop & stop & maju \\
\hline Far & Medium & Far & $\mathrm{Fa}$ & $\mathrm{Re}$ & fast & fast & stop & stop & stop & stop & stop & stop & maju \\
\hline Near & $\mathrm{Fa}$ & Far & & Green & fast & slow & stop & stop & stop & stop & stop & stop & belok kiri \\
\hline dium & Far & Far & Medium & Green & fast & $\begin{array}{c}\text { mediu } \\
\mathrm{m}\end{array}$ & stop & stop & stop & stop & stop & stop & belok kiri \\
\hline $\mathrm{F}$ & $\mathrm{Fa}$ & Fat & & Gren & fast & fast & stop & stop & stop & stop & stop & stop & naju \\
\hline
\end{tabular}

\subsection{Design Mobotsim}

Perancangan mobile manipulator ini juga disimulasikan dengan menggunakan aplikasi Mobotsim[8]. Aplikasi mobotsim ini dapat menunjukkan lintasan robot selama robot bergerak dari titik start hingga kembali ke titik start lagi [10]. Dimana bulatan yang terdapat didekat target diibaratkan sebagai pohon dan targetnya adalah 
buah yang harus diambil oleh robot. Simulasi robot dimulai dari titik start kemudian mencapai target dan berhenti sejenak, lalu berjalan ke target selanjutnya dan seterusnya hingga target selesai dan robot kembali ke posisi start awal.

Pada Gambar 7 robot berada pada titik start. Kemudian pada gambar 8(a) mobile robot berjalan dan mencapai target pertama, disini robot berhenti sejenak sebagai tanda bahwa arm robot sedang mengambil buah dan memasukkannya ke keranjang. Setelah arm robot kembali ke posisi awal, mobile robot bergerak kembali ke target kedua, seperti pada gambar 8(b) dan berhenti sejenak lagi untuk mengambil buah yang telah dipetik sebelumnya dan memasukkannya ke keranjang. Setelah arm robot kembali ke posisi awal, mobile robot bergerak kembali ke target berikutnya seperti pada gambar 8(c). Begitu seterusnya hingga gambar 8(d), gambar $8(\mathrm{e})$ sampai pada target terakhir yaitu gambar $8(f)$.

Pada Gambar 9 ini mobile robot bergerak kembali ke posisi Start awal. Selama robot bergerak dari posisi Start hingga mencapai setiap target dan kembali ke posisi Start lagi, mobile robot bergerak dengan menghindari penghalang yang terdeteksi oleh sensor jarak dan mendekati target dengan deteksi warna oleh camera yang terdapat pada end effector arm robot.

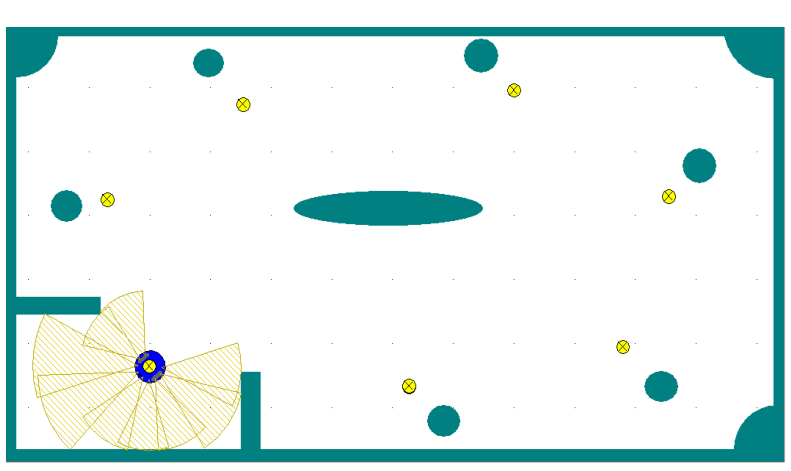

Gambar 7. Robot di Titik Start

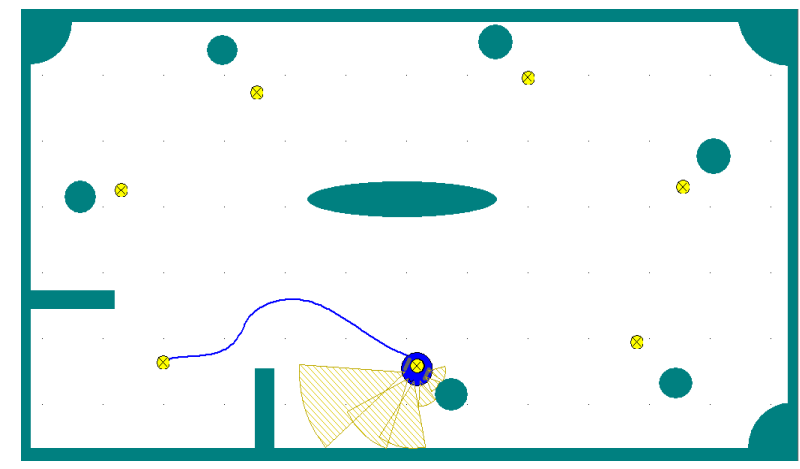

Gambar 8a. Robot pada Target Pertama

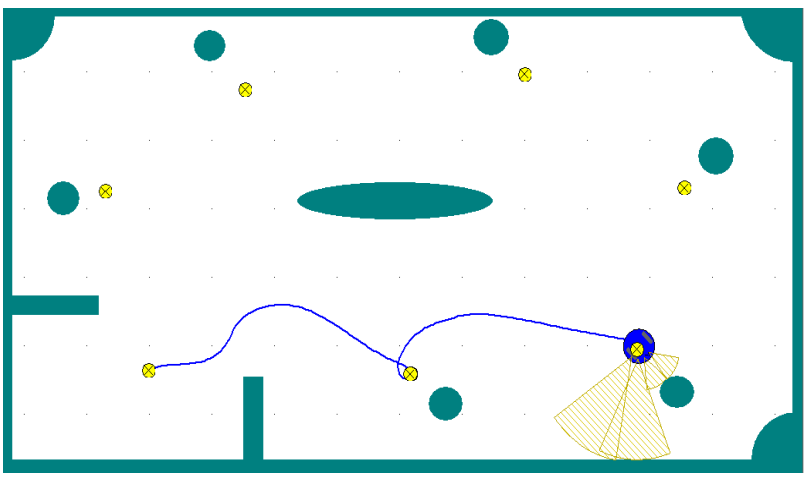

Gambar 8b. Robot pada Target Kedua

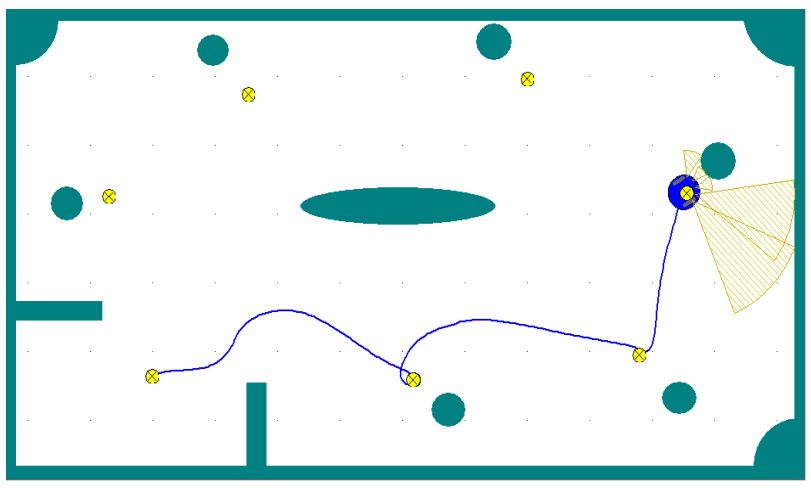

Gambar 8c. Robot pada Target Ketiga

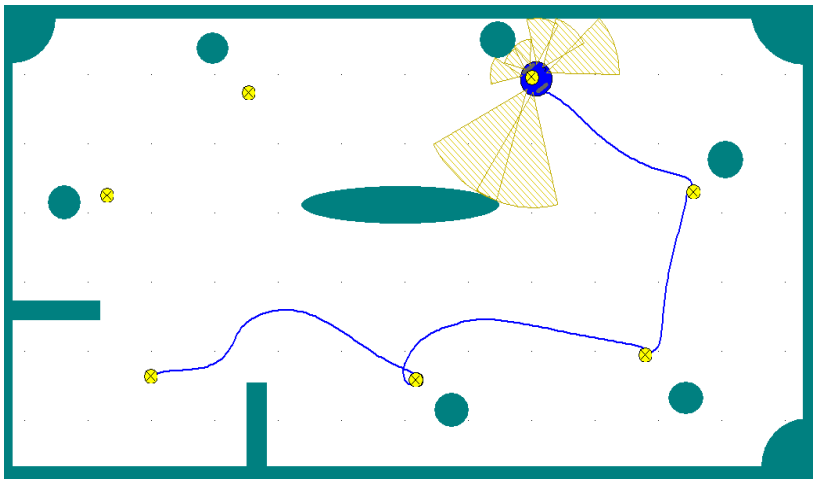

Gambar 8d. Robot pada Target Keempat



Gambar 8e. Robot pada Target Kelima 


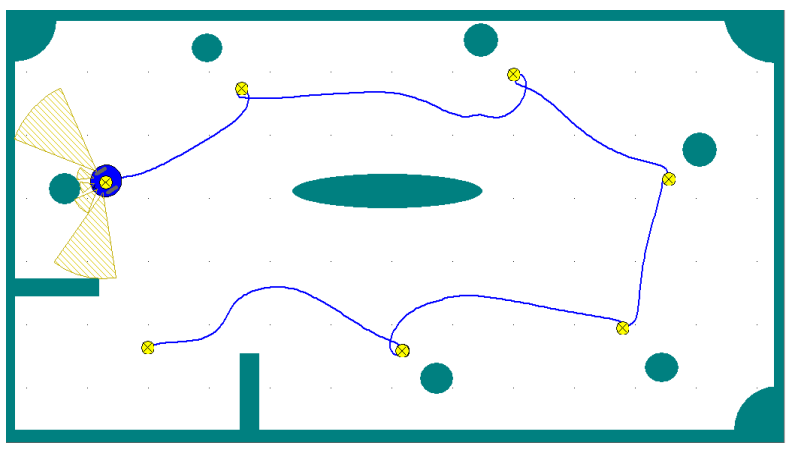

Gambar8f. Robot pada Target Keenam

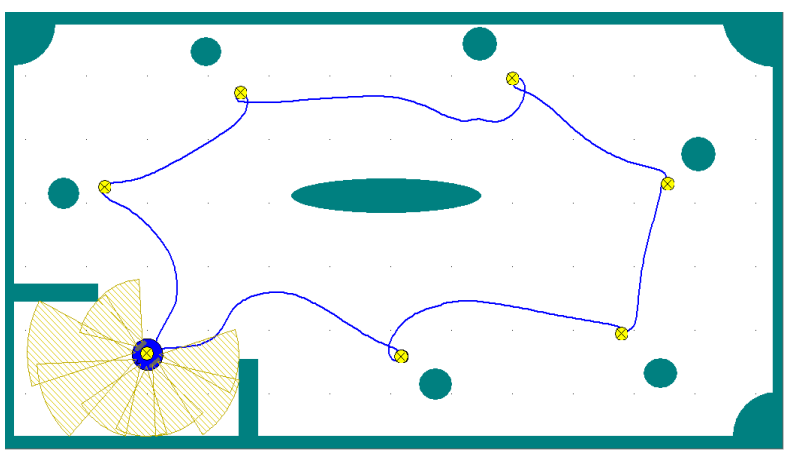

Gambar 9. Robot Kembali ke Titik Start

\section{Kesimpulan}

Pada paper ini menjelaskan bagaimana peran fuzzy logic dalam mengatur pergerakan robot mobile manipulator khususnya pada mobile robot nya. Simulasi yang digunakan pada paper ini yaitu scilab dan mobotsim [7]-[8]. Metode Fuzzy logic ini mengendalikan kecepatan motor dc berdasarkan deteksi jarak, sehingga pergerakan robot dapat teratur seperti yang terlihat jelas pada trajectory yang ada pada mobotsim.

\section{Daftar Rujukan}

[1] Hendrix R., Owan P., Garbini J., and Devasia S., 2019. Context-Specific Separable Gesture Selection for Control of a Robotic Manufacturing Assistant. IFAC PapersOnline, 51(34), pp. 89-96.

[2] Dewi T., Nurmaini S., Risma P., Oktarina Y., and Roriz M., 2019, Inverse Kinematic Analysis of 4 DOF Pick and Place Arm Robot Manipulator using Fuzzy Logic Controller, IJECE, 10(2), pp. 1376-1386. doi:10.11591/ijece.v10i2.pp1376-1386.

[3] Uchiyama N., Dewi T., and Sano S., 2014, Collision Avoidance Control for a Human-Operated Four Wheeled Mobile Robot, Proceedings of the Institution of Mechanical Engineers, Part C: Journal of Mechanical Engineering Science, 228(13), pp. 2278-2284. https://doi.org/10.1177/0954406213518523.

[4] Dewi T., Amperawan, Risma P., Oktarina Y., and Yudha D. A., 2020, Finger Cue for Mobile Robot Motion Control, Computer Engineering and Application Journal, 9(1), pp. 39-48. doi: 10.18495/COMENGAPP.V9I1.319.

[5] Uchiyama N., Dewi T., Sano S., and Takahashi H., 2014, Swarm Robot Control for Human Services and Moving Rehabilitation by Sensor Fusion, Journal of Robotics, 2014(278659), 11 pages. https://doi.org/10.1155/2014/278659.

[6] Oktarina Y., Dewi T., and Risma T., 2020, The Concept of Automatic Transport System Utilizing Weight Sensor,
Computer Engineering and Application Journal, 9(2), pp. 155-163. doi:10.18495/COMENGAPP.V0I0.339

[7] Dewi T., Risma P., Taqwa A., Rusdianasari, and Renaldi H., 2020, Experimental analysis on solar powered mobile robot as the prototype for environmentally friendly automated transportation, Proc. iCAST on Engineering Science, 24-25 Oct 2019, Bali: Indonesia, doi:10.1088/1742-6596/1450/1/012034.

[8] Dewi T., Risma P., Oktarina Y., and Muslimin S., 2018, Visual Servoing Design and Control for Agriculture Robot; a Review, pp. 57-62, Proc. 2019 ICECOS, 2-4 Oct. 2018, Pangkal Pinang: Indonesia. doi: 10.1109/ICECOS.2018.8605209.

[9] Dewi T., Risma P., and Oktarina Y., 2020, Fruit Sorting Robot based on Color and Size for an Agricultural Product Packaging System, Bulletin of Electrical Engineering, and Informatics (BEEI), 9(4), pp. 1438-1445. doi: 10.11591/eei.v9i4.2353.

[10] Oktarina Y., Dewi T., Risma P., and Nawawi M., 2020, Tomato Harvesting Arm Robot Manipulator; a Pilot Project, Journal of Physics: Conference Series, 1500, p 012003, Proc. $3^{\text {rd }}$ FIRST, Palembang: Indonesia.

[11] Al Yahmedi A.S., and Fatmi M.A., 2016. Fuzzy Logic Based Navigation of Mobile Robots," Intech, 6, pp. 111-133.

12] Nurmaini S., Tutuko B., Dewi K., Yuliza V., and Dewi T., 2017, Improving Posture Accuracy of Non-holonomic Mobile Robot system with Variable Universe of Discourse, TELKOMNIKA, 15(3). Pp. 1265-1279. doi: 10.12928/TELKOMNIKA.v15i3.6078.

[13] Dewi T., Wijanarko Y., Risma P., and Oktarina Y., 2018, Fuzzy Logic Controller Design for Leader-Follower Robot Navigation, $5^{\text {th }}$ Proc. EECSI, 5(1), pp. 298-303. 16-18 Oct 2018, Malang : Indonesia. doi:10.1109/EECSI.2018.8752696.

14] Dewi T., Risma P., and Oktarina Y., 2018, Fuzzy Logic Simulation as a Teaching-learning Media for Artificial Intelligence Class, Journal of Automation Mobile Robotics and Intelligent Systems, 12(3), pp. 3-9.doi: 10.14313/JAMRIS 3-2018/13

[15] Dewi T., Oktarina Y., Risma P., and Kartini S., 2019, Desain Robot Pengikut Manusia Sederhana dengan Fuzzy Logic Controller, Proc. Annual Research Seminar (ARS), 5(1), pp. 12-16, 16 Nov 2019, Palembang: Indonesia.

16] Oktarina Y., Septiarini F., Dewi T., Risma P., and Nawawi M., 2019, Fuzzy-PID Controller Design of 4 DOF Industrial Arm Robot Manipulator, Computer Engineering and Application Journal, 8(2), pp. 123-136. doi: 10.18495/COMENGAPP.V8I2.300.

17] Dewi T., Sitompul C., Risma P., Oktarina Y., Jelista R., Mulyati M., 2019, Simulation Analysis of Formation Control Design of Leader-Follower Robot Using Fuzzy Logic Controller, Proc 2019 ICECOS, 2-3 Oct. 2019, Batam Island: Indonesia. doi:10.1109/ICECOS47637.2019.8984433.

[18] Farooq U., Amar M., Asad M.U., Hanif A., and Saleh S.O., 2014. Design and Implementation of Neural Network of Based Controller for Mobile Robot Navigation in Unknown Environment. International Journal of Computer and Electrical Engineering, 6(2), pp. 83-89. doi:10.7763/IJCEE.2014.V6.799

[19] Yudha H. M., Dewi T., Hasana N., Risma P., Oktarina, Y. Kartini S., 2019, Performance Comparison of Fuzzy Logic and Neural Network Design for Mobile Robot Navigation, Proc. 2019 ICECOS, 2-3 Oct. 2019, Batam Island: Indonesia. doi:10.1109/ICECOS47637.2019.8984577

[20] Larasati N., Dewi T., and Oktarina Y., 2017. Object Following Design for a Mobile Robot using Neural Network. Computer Engineering and Application Journal, 6(1), pp. 5-14. doi:10.18495/COMENGAPP.V6I1.189.

[21] Dewi T., Risma P., Oktarina Y., and Roseno M.T., 2017. Neural Network Design for a Mobile Robot Navigation a Case Study. 4th Proc. EECSI. 23-24 Sep. 2017. Yogyakarta: Indonesia. doi:10.1109/EECSI.2017.8239168.

[22] Dewi T., Risma P., Oktarina Y., and Nawawi M., 2017. Neural Network Simulation for Obstacle Avoidance and Wall Follower Robot as a Helping Tool for Teaching-Learning Process in Classroom. 1st Proc. ICEAT, 29-30 November 2017, Mataram: Indonesia. doi:10.1088/1757-899X/403/1/012043

[23] Risma P., Dewi T., Oktarina Y., and Wijanarko Y., 2019. Neural Network Controller Application on a Visual based Object Tracking and Following Robot. Computer Engineering and Application Journal, 8(1). doi: 10.18495/COMENGAPP.V8I1.280. 
[24] Kuswad S., Natasya A., Tamara M.N., and Adji I., 2018. Optimasi Sistem Navigasi Robot Bencana Dengan Algoritma Bug Dan Jaringan Syaraf Tiruan. JTIIK, . 5(5), pp. 635-642.

[25] Savage J., Muoz S., Matamoros M., and Osorio R., 2013 Obstacle Avoidance Behaviors for Mobile Robots Using Genetic Algorithms and Recurrent Neural Networks. IFAC, 46(24), pp. 141-146. 